Lars Bülow* and Philip C. Vergeiner

\title{
Intra-individual variation across the lifespan: Results from an Austrian panel study
}

https://doi.org/10.1515/lingvan-2020-0026

\begin{abstract}
This article explores intra-individual variation and language change across the lifespan of eight speakers from a small Austrian village. Four phonological variables in two settings (informal conversation vs. formal interview) are traced across longitudinal panel data that span 43 years. The analysis reveals an increase of dialect features (retrograde change), even though apparent-time as well as real-time trend studies indicate dialect loss in the Bavarian speaking parts of Austria. The panel data also indicate that neither the group means at one moment in time nor their averaged changes are representative of the intra-individual variation of any of the eight speakers. Regarding this non-representativity, the article introduces the classical ergodic theorem to variationist sociolinguistics. Evidence will be provided that change across the lifespan of an individual is a non-ergodic process. Thus, it is argued that variationists have to be more cautious when they generalise from group-derived estimates to individual developments and vice versa.
\end{abstract}

Keywords: change across the lifespan, ergodicity, intra-individual variation, panel research, retrograde change

\section{Introduction}

Variationist sociolinguists tend to use two techniques to study change in progress: the apparent-time approach and the real-time approach. According to the apparent-time construct, one can use "the present to explain the past" (Labov 1975): ongoing changes can be traced by comparing the use of linguistic variables by different generations at one moment in time. To study language change in real time, researchers contrast older data with more recent data, either by (1) re-examining a community through a trend study or by (2) re-examining the same informants through a panel study.

Since panel studies bring serious practical problems (e.g. the amount of time required, particularly regarding the limitations of short-term project funding), variationists tend to use the apparent-time and/or the real-time trend design. As a result of the missing panel research in linguistics, Buchstaller and Wagner (2018: 2) point out that "the degree to which the grammar of individual speakers changes across the lifespan could not - or could only very indirectly - be investigated". Today, more and more variationists acknowledge the lack of panel research as one of the crucial desiderata to link the group level with the individual (Bergs, this special issue).

This article aims to underline the importance of studying variation and change across the individual lifespan to better understand language change in progress. Therefore, it first provides arguments as to why apparent-time (and real-time trend) studies are not sufficient to separate changes on the individual level from changes on the group level. The article then describes different trajectories in individual speakers, before relating to the ergodicity problem as a challenge for studying language variation and change. In a nutshell, the ergodic theorem "deals with the generalizability of statistical phenomena across levels and units of analysis" (Fisher et al. 2018: 1). It stipulates that inferences based on group-derived estimates can only be generalised to individual behaviour over time if the process is ergodic (Molenaar and Campbell 2009). This requires that the structure of inter-individual variation is equivalent to the structure of intra-individual variation over time (Section 2.3 provides definitions and more details).

\footnotetext{
*Corresponding author: Lars Bülow, University of Vienna, Vienna, Austria, E-mail: lars.buelow@univie.ac.at Philip C. Vergeiner, University of Salzburg, Salzburg, Austria
}

Ә Open Access. $\odot 2020$ Lars Bülow and Philip C. Vergeiner, published by De Gruyter. $(\Subset)$ BY This work is licensed under the Creative Commons Attribution 4.0 International License. 
Based on panel data of eight Austrian speakers, which will be analysed against the backdrop of the community trend (or group trend), the present article provides empirical evidence that change across the lifespan of an individual is a non-ergodic process. By raising awareness of the ergodicity problem our aim is not to reject but rather complement the frameworks and approaches developed in recent decades.

The present study is part of the Ulrichsberg project (Wallner in prep.), which is based on a panel corpus that spans 43 years and incorporates 12 speakers (six males/six females). Each of them was recorded in 1975/76 and re-recorded in 2018/19 in two settings: a formal interview and an informal conversation among friends. For the present study, we analyse four phonological variables (see Section 4) produced by eight (four males/four females) of the 12 speakers in both settings. Our analysis is guided by the following three questions: (1) Do speakers adapt to phonological changes that can be observed at the community level? (2) Do we find inter- and intra-individual differences over time? (3) Does the process meet the ergodicity requirements, i.e. how similar is the structure of inter-individual variation to the structure of intra-individual variation?

\section{Language variation and change across the lifespan - Techniques, interpretations and problems}

In this section, we first argue why apparent-time (and real-time trend) studies cannot sufficiently disentangle changes on the group level from changes on the individual level (Section 2.1). In Section 2.2, we then explain different trajectory types in individual speakers, before we introduce the ergodicity problem in Section 2.3.

\subsection{The apparent-time construct}

Labov (1966) introduced the apparent-time construct claiming that synchronic variation between age cohorts may reflect ongoing changes. Even though many studies have confirmed the general utility of this construct (Bailey et al. 1991), others have made the point that it merely needs some revision. Two major problems were highlighted: first, the apparent-time interpretation of age differences depends strongly on the assumption that individual repertoires remain fairly stable after adolescence. This assumption is challenged by recent panel studies (e.g. Sankoff and Blondeau 2007; Wagner and Sankoff 2011) showing "that some adults change their speech as they age, and that changes can occur at many levels of the grammar” (Wagner 2012: 379). Second, if such changes on the individual level (e.g. age-grading) exist, apparent-time studies cannot adequately separate them from changes on the group level (e.g. generational change) as they rely on group comparisons only (Sankoff 2019; Figure 1).

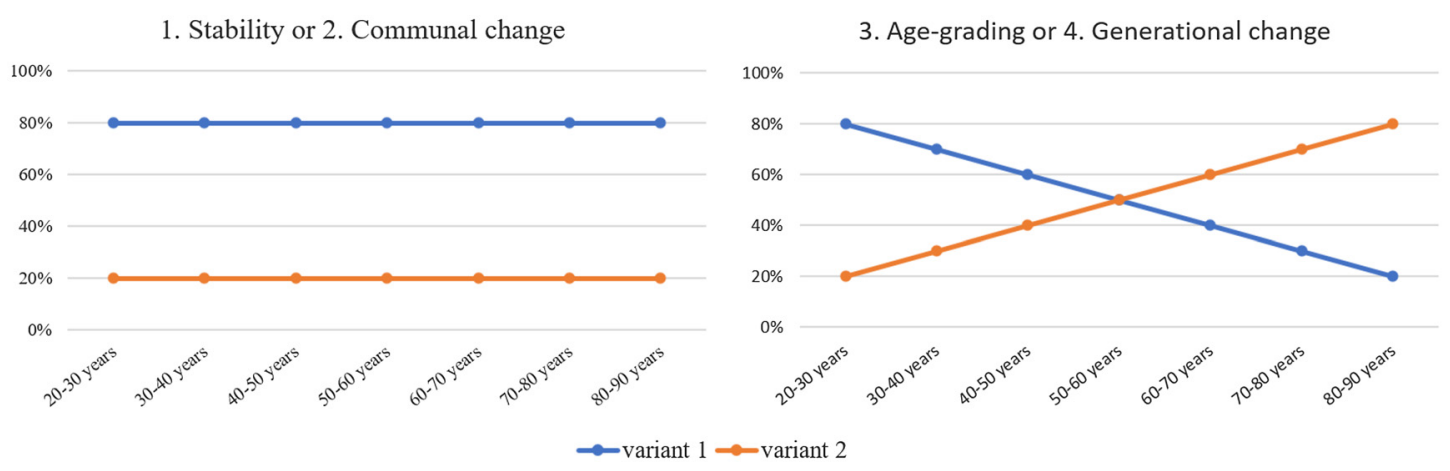

Figure 1: Idealised distribution of variables plotted against speaker age. 
To elaborate, Labov (1994: 83) offered four interpretive possibilities of synchronic group-level snapshots, which plot the distribution of variables against speaker age (Table 1):

Table 1: Possible interpretations of synchronic age distributions (adapted from Labov [1994:83]).

\begin{tabular}{llll}
\hline Synchronic age distribution & Individual & Community & Interpretation \\
\hline (1) Flat pattern & stable & stable & stability \\
(2) Flat pattern & changing & changing & communal change \\
(3) Increasing/decreasing slope with age & changing & stable & age-grading \\
(4) Increasing/decreasing slope with age & stable & changing & generational change \\
\hline
\end{tabular}

(1) A flat pattern may indicate that no change is going on ('stability') or

(2) that all the speakers in the community are rapidly changing regardless of their age ('communal change').

(3) A monotonic slope with age may indicate that the community as a whole remains stable, though individuals change in a recurrent and systematic manner as they are getting older ('age-grading'), but

(4) it might also show an apparent-time effect so that with each age-cohort the use of a particular variant increases or decreases, leading to a long-term change within the speech community, even though individual speakers remain stable over time ('generational change').

Figure 1, which visualises the above-mentioned patterns, indicates that it is challenging from an apparent-time perspective to disentangle 'stability' from 'communal change' and 'age-grading' from 'generational change'. The obvious reason is that apparent-time studies cannot gather individual linguistic changes which would be necessary to distinguish 'communal change' and 'age-grading'. Leaving aside more performance-oriented approaches (e.g. third wave sociolinguistics, cf. Eckert [2000]), the best design to control for individual linguistic variability and instability are panel studies (Sankoff 2019). We will discuss their advantages in the following section.

\subsection{Panel studies}

In the last two decades, a number of panel studies have been conducted which facilitate our understanding of changes across the lifespan. The majority of them follows one individual (e.g. Harrington et al. 2000) or a few speakers (e.g. Buchstaller 2016; de Decker 2006; Rickford and Price 2013). There are also some large-scale panel studies structured by socio-demographic categories (e.g. Gregersen 2009; Sankoff and Blondeau 2007; van Hofwegen and Wolfram 2010).

These studies have already begun to answer important questions regarding language change in progress and individual language development. Their results have demonstrated, for example, that more than the four patterns given by Labov (1994: 83; Table 1) exist. Beside the two patterns which should show stable trajectories in individuals ('stability', 'generational change'), we have to take into account three dynamic trajectory types in individual speakers (Table 2):

Table 2: Dynamic trajectory types in individual speakers.

\begin{tabular}{llll}
\hline Trajectory type in the individual speaker & Individual & Community & Interpretation \\
\hline (1) Increase/decrease slope with age while the community is stable & changing & stable & age-grading \\
(2) Increase/decrease slope in the direction of community change & changing & changing & lifespan change \\
(3) Decrease/increase slope against the direction of community change & changing & changing & retrograde change \\
\hline
\end{tabular}


(1) 'Age-grading' is defined as individual linguistic change against the backdrop of community stability (Labov 1994: 83).

(2) Individual changes in which speakers "make post-adolescent adjustments to their speech in the direction of community change" (Wagner 2012: 377), which is typically driven by younger speakers, are referred to as 'lifespan change' (Sankoff 2005) (note that lifespan change does not necessarily indicate a flat pattern at the community level as in the case of 'communal change', see Table 1).

(3) Panel studies also reveal individual changes against the community trend, so-called 'retrograde change' (Wagner and Sankoff 2011). In this scenario, speakers mostly turn towards conservative variants after retirement (Sankoff 2013: 269).

In sum, while apparent-time snapshots might help identify variables that show ongoing language change, panel data facilitate adequate interpretations of these changes taking into account individual linguistic developments. However, apparent-time studies not only have the problem that they solely rely on synchronic data, they also face the problem of making inferences from group comparisons only. The latter problem also holds for trend studies. Because the issues that arise from group comparisons are rarely discussed or acknowledged in variationist sociolinguistics, we elaborate on this point in the following section.

\subsection{Ergodicity}

Taking into account the already mentioned ergodic theorem, research in applied linguistics (Larsen-Freeman and Cameron 2008; Lowie 2017; Lowie and Verspoor 2019) as well as developmental psychology (Fisher et al. 2018; Molenaar and Campbell 2009; van Geert 2011) has shown that results derived from group comparisons can only be individualised under certain conditions. In particular, the structure of inter-individual variation has to be asymptotically equivalent to the structure of intra-individual variation over time (homogeneity and stationarity). In other words, their time averages need to be the same as their averages over the probability space; e.g. when the outcome is the same if I roll a dice 1,000 times or 1,000 dice at one moment in time. Thus, "generalizations that rely on group estimates are nonergodic if there are individual exceptions" (Fisher et al. 2018: 1).

Non-linear processes, such as psychological and sociological phenomena which are organised within persons over time, are non-ergodic by nature. Because language development is also a non-linear process (e.g. Lowie 2017: 127), we argue that studies based on the inter-individual group level alone rely on inadequate assumptions. Consequently, both apparent-time and real-time trend evidence should be validated with panel data, ideally having many data points of the same individuals over time (Lowie 2017: 130; Lowie and Verspoor 2019). It is important to study intra-individual variation, defined here as variation over time of the same speaker in the same style of speech, for its own sake. In what follows, we do so by investigating the changes across the lifespan of eight speakers from a small Austrian village.

\section{Design, data, and sampling}

Our study examines the use of four phonological variables over the life-course of eight speakers against the backdrop of the community-wide trend in Austria's East Central Bavarian dialect area. The data analysed (Figure 2) are part of the Ulrichsberg corpus (Wallner in prep.).

All speakers were born and raised in Ulrichsberg, a small village in Upper Austria with 1,137 inhabitants. Although they have different socio-demographic backgrounds (Table 3, see Wallner in prep. for more details), none of them has left Ulrichsberg for a longer period. 


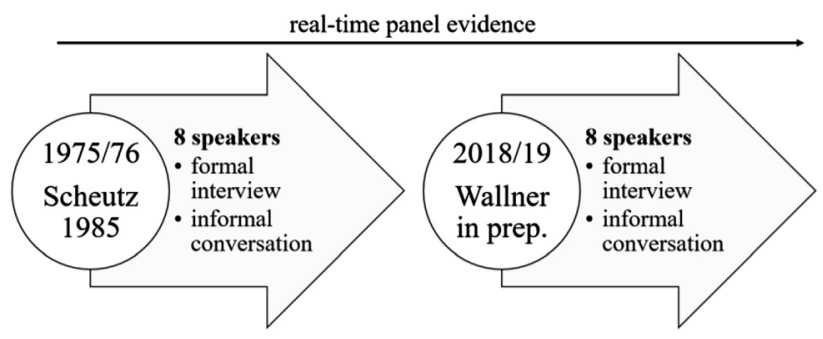

Figure 2: Real-time panel design.

Table 3: Speakers' socio demographic background.

\begin{tabular}{|c|c|c|c|}
\hline Speaker 1 & Speaker 2 & Speaker 3 & Speaker 4 \\
\hline $\begin{array}{ll}1943 \\
-\quad \text { female } \\
-\quad \text { high level of education } \\
-\quad \text { entrepreneur }\end{array}$ & $\begin{array}{ll}1941 \\
-\quad \text { male } \\
-\quad \text { secondary education } \\
-\quad \text { merchant }\end{array}$ & $\begin{array}{l}1941 \\
-\quad \text { female } \\
-\quad \text { secondary education } \\
-\quad \text { merchant }\end{array}$ & $\begin{array}{ll}1942 \\
-\quad \text { male } \\
-\quad \text { secondary education } \\
-\quad \text { farmer }\end{array}$ \\
\hline Speaker 5 & Speaker 6 & Speaker 7 & Speaker 8 \\
\hline $\begin{array}{ll}1942 \\
-\quad \text { female } \\
-\quad \text { secondary education } \\
-\quad \text { farmer }\end{array}$ & $\begin{array}{ll}1950 \\
-\quad \text { male } \\
-\quad \text { secondary education } \\
-\quad \text { municipality officer }\end{array}$ & $\begin{array}{ll}1944 \\
-\quad \text { male } \\
-\quad \text { secondary education } \\
-\quad \text { municipality officer }\end{array}$ & $\begin{array}{ll}1946 \\
-\quad \text { female } \\
-\quad \text { secondary education } \\
-\quad \text { saleswomen }\end{array}$ \\
\hline
\end{tabular}

All speakers were originally recorded in 1975/76 in both a formal interview and an informal conversation (Scheutz 1985). As part of the ongoing project "Variation and change of dialect varieties in Austria (in real and apparent time)", 1 we created a second time slice by re-recording the participants in 2018/19 (Wallner in prep.). The re-examination replicated the structure of the original recordings as closely as possible, trying e.g. to carefully recreate the original interview situation of the first study, including the location, the types of questions asked and the social and linguistic characteristics of the initial field worker.

\section{The variables under investigation}

The scope of this study encompasses variation in four phonological variables. The variants account for important differences between Austrian Standard German (S) and Central Bavarian dialects (D). They were chosen because they occur frequently and are easily distinguishable acoustically. Table 4 summarises the variables under investigation, their variants and some illustrative examples. For a more detailed description of the variables and their historical development, see Kranzmayer (1956); Scheutz (1985) or Scheuringer (1990).

Table 4: Variables and variants.

\begin{tabular}{|c|c|c|c|c|}
\hline & Variables & S-variant(s) & D-variant(s) & Examples \\
\hline $\mathrm{V} 1$ & MHG ei & [ac] & [วе] , [a:] & [tsvac] $\Leftrightarrow[$ tsvวe], [tsva:] ('two') \\
\hline V2 & Derounding & {$[\varnothing:,, y:, Y, ગ ા]$} & 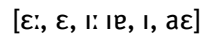 & [hø:en] $\Leftrightarrow$ [he:en] ('hear') \\
\hline V3 & Word final / $\mathrm{x} /$ in monosyllables & {$[\mathrm{x}, \mathrm{c}]$} & $\varnothing$ & {$[\mathrm{m} ı c ̧] \Leftrightarrow[\mathrm{m} \mathrm{l}]\left({ }^{\prime} \mathrm{me}\right.$ ') } \\
\hline V4 & Word final / $\mathrm{x} /$ in the suffix -lich & [lıç] & {$[\mathrm{ll}]$} & [ægntlıç] $\Leftrightarrow$ [ægntlı] ('actually’) \\
\hline
\end{tabular}

1 See Deutsch in Österreich (DiÖ) 'German in Austria', https://dioe.at/. 
The first two variables are vocalic: V1 relates to the realisation of the vowels which have historically developed from Middle High German ei, V2 refers to the occurrence of rounded or derounded vowels in the context of New High German /ö/, / ̈̈/ and /oi/. V3 and V4 are of consonantal nature: they are concerned with word-final deletion or preservation of the allophonic fricative $/ \mathrm{x} /$ in frequent monosyllables (like ich ' $\mathrm{I}$ ', auch 'also, too', doch 'yet, but') as well as the suffix -lich. The subdivision between V3 and V4 is required due to lexical diffusion regarding the accomplishment of the deletion (Scheuringer 1990: 246; Scheutz 1985: 170).

\section{Results}

For each of the variables we will first investigate the real-time differences with a focus on supra-individual tendencies (Section 5.1). Thereby we deal with real-time differences in each situation (formal and informal) independently but leave synchronic stylistic differences aside. They are reported in Vergeiner et al. (accepted). Thereafter, we contrast the real-time differences with individual patterns of variation and change (Section 5.2). Particularly Section 5.2 is attributed to the ergodicity problem in that we control for the consistency between individual and group variability.

\subsection{Real-time differences}

For the two vocalic variables, V1 and V2, we found real-time differences only in the formal setting, as is indicated by Figure 3 (for V1) and Figure 4 (for V2). Each figure shows the relative number of standard variants per speaker (S) for the formal (left) and the informal situation (right). For the formal situation, as can be seen

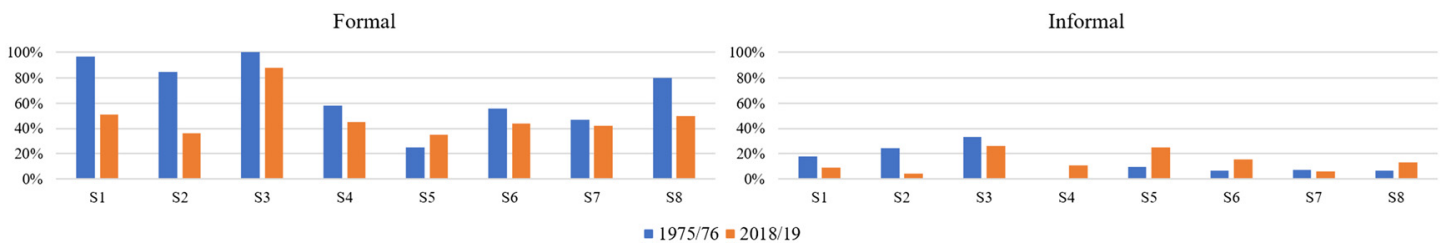

Figure 3: V1 real-time differences for the formal setting (left) and informal setting (right).

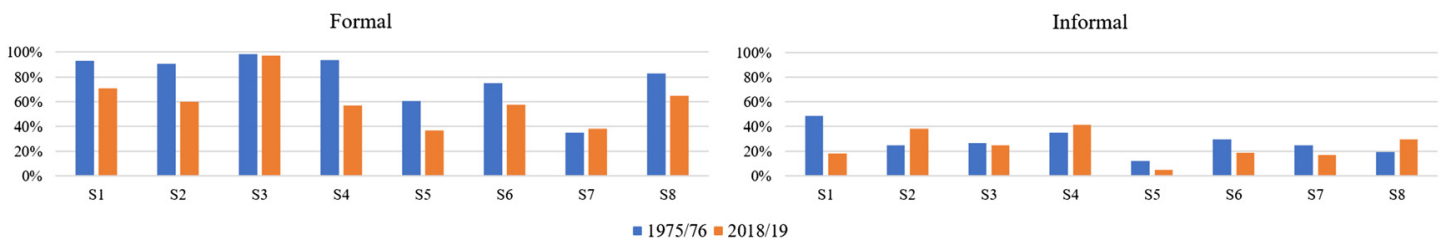

Figure 4: V2 real-time differences for the formal setting (left) and informal setting (right).

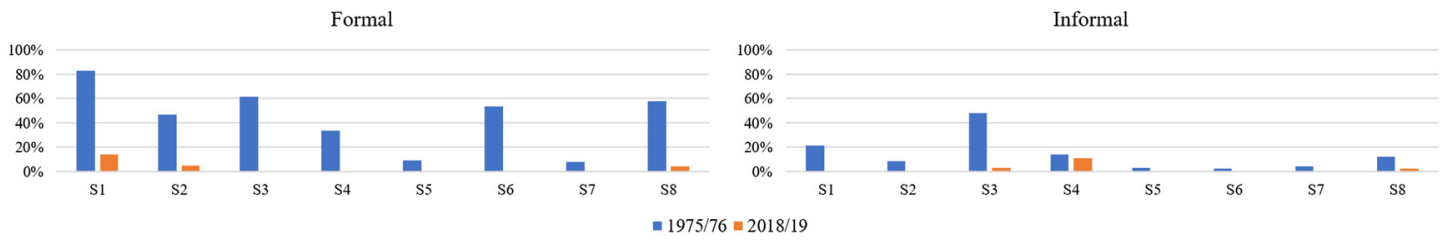

Figure 5: V3 real-time differences for the formal setting (left) and informal setting (right). 
Table 5: Significant real time differences ( $p$-values based on Wilcoxon signed rank tests; ${ }^{*}$ signifies significant results).

\begin{tabular}{lrrrr}
\hline Real-time difference & Formal & \multicolumn{2}{r}{ Informal } \\
\cline { 2 - 5 } & $\boldsymbol{p}$ & $\boldsymbol{z}$ & $\boldsymbol{p}$ & $\boldsymbol{Z}$ \\
\cline { 2 - 5 } & $0.025^{*}$ & -2.240 & 0.889 & -0.140 \\
V1 & $0.025^{*}$ & -2.240 & 0.575 & -0.560 \\
V3 & $0.012^{\star}$ & -2.521 & $0.012^{\star}$ & -2.521 \\
V4 & $0.018^{*}$ & -2.366 & $0.025^{*}$ & -2.240 \\
\hline
\end{tabular}

from both figures, seven out of eight speakers used more standard features in the 1975/76 recordings. These differences are statistically significant (see Table 5). There are no such differences in the informal setting.

For the two consonantal variables, the data reveal significant real-time differences for both settings. Regarding V3, every speaker used more standard forms with /x/ in 1975/76 than in 2018/19 (Figure 5). In case of

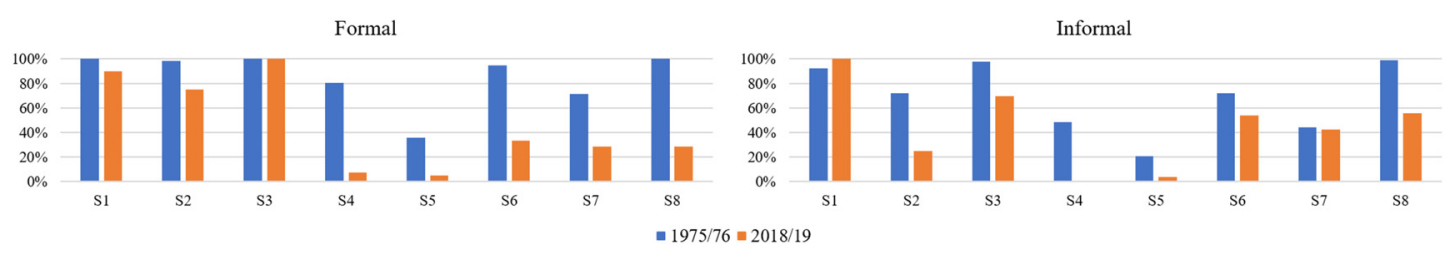

Figure 6: V4 real-time differences for the formal setting (left) and informal setting (right).

V4 seven out of eight speakers did so (Figure 6). Only speaker 1 displays more standard forms in the informal setting in the 2018/19 recordings.

The general results confirm that all eight speakers are unstable in their language use over time. In particular, the differences indicate that the speakers tend to use more dialect features in the 2018/19 recordings, which applies particularly in the case of the formal situations. This is remarkable inasmuch as most apparent-time as well as real-time trend studies have shown dialect loss to be the general trend in the Bavarian speaking parts of Austria (e.g. Scheuringer 1990; Scheutz 1985). Because of the increase of dialect features, which runs against the community trend, we have to acknowledge retrograde change for our speakers (Section 2.2).

\subsection{The ergodicity problem}

Because retrograde changes indicate that the language usage of our eight speakers is not stable (the means and variances changed between the recordings) we have to take seriously the ergodicity problem. As indicated in Section 2.3, it is problematic to project variation and change at the group level to the development of individuals if the linguistic development of individuals is non-ergodic (Bülow et al. 2019). The empirical proof of such concerns can only be achieved by panel studies in which we compare group means with individual performances over time. Thus, panel studies are urgently needed to validate results from group studies. In what follows we compare the real-time changes of each individual with the group means.

At first glance, the individuals' trajectories as well as most of the group means show certain common tendencies - in particular a decrease of standard features, with a steeper slope for the formal setting compared to the informal setting. Nonetheless, a more detailed comparison reveals remarkable inter-individual differences for all four variables, as Figure 7 shows. It illustrates the real-time differences per variable and situation for each speaker in comparison to the averaged real-time differences (in red). 


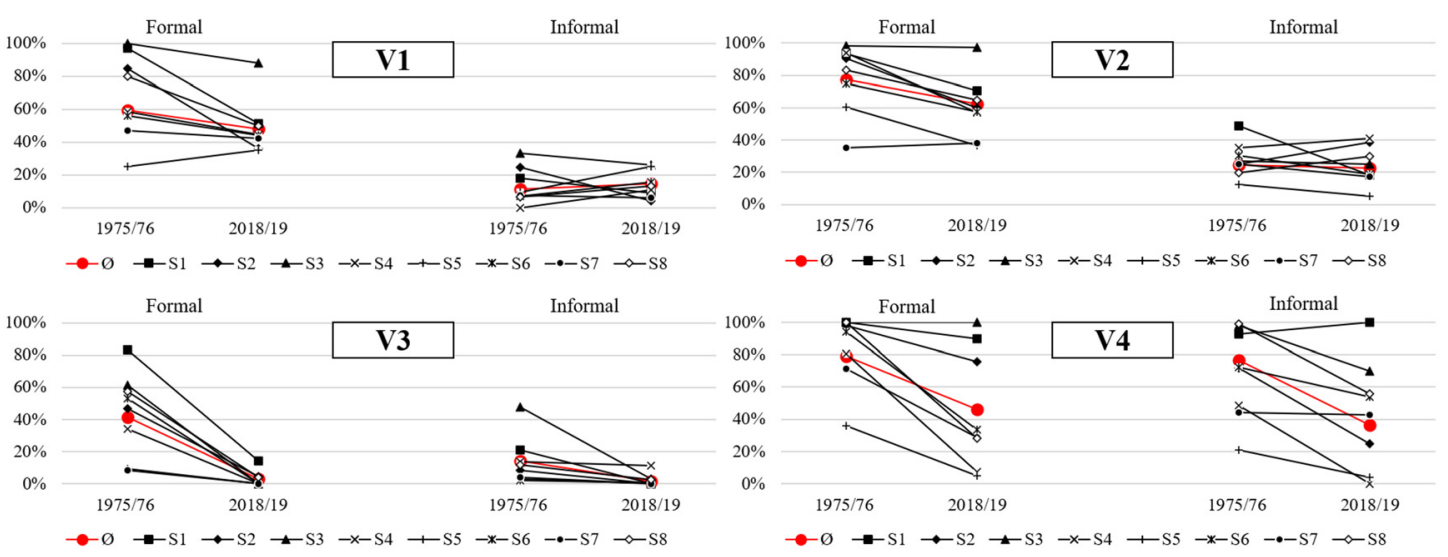

Figure 7: Comparison of the real-time differences of each individual with the group means.

The mean values in Figure 7 reflect the individual's language development in not a single case: Not only do the initial and final values differ with respect to each speaker (hence the rather large standard deviations; Table 6) but also the average distances between them, as Table 7 shows. In particular, Table 7 indicates that the averaged real-time differences (again per variable and situation) are not met by any speaker. Some speakers show much higher, others much lower degrees of change. Some display - at least for single variables - even different directions of change, e.g. an increase instead of a decrease.

One can illustrate this point by looking at the real-time differences of V1 in the formal setting: S1, for example, used a rather high amount of standard forms in 1975/76. This speaker applied much fewer of these forms (46\%) in 2018/19. Although this low value of S1 in 2018/19 approximates the average for the 2018/19 recordings, neither the initial value in 1975/76 nor the differences between the initial and the final value do. In contrast, S3 also shows a high value for V1 in 1975/76, but a just slightly reduced value for the 2018/19 recordings. Although both S3's initial and final values differ from the average, the distance between both values is gently sloping, getting close to the average difference.

Table 6: Standard deviations.

\begin{tabular}{lrrrrr}
\hline Setting & Year of recording & V1 & V2 & V3 & V4 \\
\hline Formal setting & $\mathbf{1 9 7 5 / 7 6}$ & $25 \%$ & $20 \%$ & $24 \%$ & $21 \%$ \\
& $\mathbf{2 0 1 8 / 1 9}$ & $16 \%$ & $18 \%$ & $14 \%$ & $27 \%$ \\
Informal setting & $\mathbf{1 9 7 5 / 7 6}$ & $10 \%$ & $10 \%$ & $5 \%$ & $35 \%$ \\
& $\mathbf{2 0 1 8 / 1 9}$ & $8 \%$ & $11 \%$ & $4 \%$ & $32 \%$ \\
\hline
\end{tabular}

Table 7: Amount of individual and average increase/decrease of standard forms.

\begin{tabular}{|c|c|c|c|c|c|c|c|c|}
\hline \multirow[t]{2}{*}{ Real-time differences $\left(=X_{1975 / 76}-X_{2018 / 19}\right)$} & V1 & V2 & V3 & V4 & V1 & V2 & V3 & V4 \\
\hline & \multicolumn{4}{|c|}{ Formal setting } & \multicolumn{4}{|c|}{ Informal setting } \\
\hline $\mathrm{S} 1$ & $-46 \%$ & $-23 \%$ & $-69 \%$ & $-10 \%$ & $2 \%$ & $-1 \%$ & $-12 \%$ & $1 \%$ \\
\hline $\mathrm{S} 2$ & $-49 \%$ & $-30 \%$ & $-42 \%$ & $-23 \%$ & $-7 \%$ & $-2 \%$ & $-45 \%$ & $-28 \%$ \\
\hline $\mathrm{S} 3$ & $-12 \%$ & $-1 \%$ & $-62 \%$ & $0 \%$ & $-5 \%$ & $-19 \%$ & $-19 \%$ & $-37 \%$ \\
\hline $\mathrm{S} 4$ & $-14 \%$ & $-37 \%$ & $-34 \%$ & $-74 \%$ & $8 \%$ & $-11 \%$ & $-1 \%$ & $-18 \%$ \\
\hline S5 & $10 \%$ & $-24 \%$ & $-9 \%$ & $-31 \%$ & $-19 \%$ & $-8 \%$ & $-8 \%$ & $-29 \%$ \\
\hline S6 & $-12 \%$ & $-17 \%$ & $-53 \%$ & $-61 \%$ & $4 \%$ & $4 \%$ & $-14 \%$ & $-24 \%$ \\
\hline S7 & $-5 \%$ & $3 \%$ & $-8 \%$ & $-43 \%$ & $18 \%$ & $-20 \%$ & $-4 \%$ & $-40 \%$ \\
\hline S8 & $-30 \%$ & $-18 \%$ & $-53 \%$ & $-72 \%$ & $1 \%$ & $29 \%$ & $8 \%$ & $-21 \%$ \\
\hline Mean & $-18 \%$ & $-20 \%$ & $-41 \%$ & $-39 \%$ & $-4 \%$ & $0 \%$ & $-12 \%$ & $-24 \%$ \\
\hline
\end{tabular}


But it is not the inter-personal comparison alone that is remarkable. The data show also a great amount of intra-individual variation. This is shown by the fact that each speaker behaves differently with regard to each variable. While S1, for example, shows a rather large decrease in the number of standard forms for V1, this is not true for V2. S4 behaves the other way around: Here the number of standard forms of V1 is rather slightly decreasing, whereas we see a larger drop in relation to V2. These observations lead to the impression of unforeseeable, if not chaotic, individual trajectories, confirming our initial hypothesis that we are faced with non-ergodic developments.

\section{Discussion}

Because we have little knowledge of how language variation and change on the community level affect individuals' developments, our main goal was to investigate intra-individual variation and change across the lifespan of eight speakers against the backdrop of the community trend. Evidence from apparent-time and trend studies indicates dialect-levelling or even dialect loss as a general trend in Upper Austria (Scheutz 1985; Scheuringer 1990). For this reason, one would expect an increase of standard features accompanied by a decrease of stylistic differences.

Surprisingly, the panel study exposed retrograde change for all eight speakers to varying degrees. In particular in the formal setting the speakers used more dialect features in 2018/19 than in 1975/76. ${ }^{2}$ Retrograde change, therefore, also indicates a decrease of stylistic differences in the opposite direction of the supposed community trend.

As a general result, our study indicates that it is necessary to slightly revise the findings that have been acquired from apparent-time as well as trend studies. In accordance with Wagner and Sankoff (2011) and their findings of retrograde change, it is recommended to rethink the rate of ongoing changes on the community level. Regarding their data on Montréal French, Wagner and Sankoff (2011: 305) state that an apparent-time interpretation would "overestimate the actual pace of change (taking usage rates of elderly speakers to represent the state of the language when they acquired it would picture these speakers as 'farther back' than they actually were as children, so the 'distance' between that stage and the present would appear to be greater than it actually was)".

As we have argued, real-time trend studies can only offer limited insights to readjust apparent-time interpretations. Our analysis has shown that the mean values of group data over time do not necessarily reflect individual developments (Pfenninger, this special issue). Furthermore, each speaker shows intraindividual variation depending on the setting and each variable. One cannot attribute this (solely) to sociodemographic factors as two speakers with a similar background can behave and develop differently (Wallner in prep. provides more details). This observation of speaker-specific processes (retrograde change) also violates one of the ergodicity requirements (Section 2.3). Remember that "ergodicity can only be assumed when the means as measured over time are constant, so that the scores are homogenous in time, and when the dynamic process shaped by the interaction of variables over time is the same for all participants, so that the process is homogenous across different subjects" (Lowie 2017: 127-128). This is definitely not the case for our data, as the results in Section 5.2 show. Again, our findings indicate that apparent-time studies as well as trend studies overestimate the accuracy of aggregated group data. Thus, we have to follow Molenaar and Campbell's (2009: 116) advice: "Whenever person-specific processes are involved, and insofar as these processes are nonergodic [...], their analysis should be based on intraindividual variation" and not on interindividual comparison. Only a panel design, ideally having many data points of the same individual over time (Lowie 2017: 130), explicitly tests for the equivalence of processes at the individual and the group level over time. One key challenge for future variationist sociolinguistic research is to conduct data that allow for time-series analysis - or, as Lowie (2017: 123) summarises, "if we are interested in investigating the changing

2 Note that studies in cognitive psychology reveal that performances across the lifespan might be highly task-dependent (Fagot et al. 2018). 
relations in complex adaptive or dynamical systems, we should use nonlinear analyses of longitudinal data in which the denseness of the observations is adjusted to the expected rate of development”.

\section{Conclusion}

This panel study gave first insights into intra-individual variation across the lifespan of eight Austrian speakers. Surprisingly, the real-time differences revealed retrograde changes. The panel data, further, highlighted that the intra-individual variation on the individual level is not equivalent to the inter-individual variation on the group level. Thus, group-derived estimates cannot be generalised to individual language usage and vice versa (Bülow et al. 2019; Lowie 2017). Finally, we conclude that lifespan change is a non-ergodic process that cannot adequately be researched on the basis of group comparisons alone.

Therefore, many more qualitative and quantitative panel studies are needed to better link the group level with the individual level. Such research can help, for example, to explore the mechanisms which lead speakers to revert to conservative linguistic features and why some speakers tend more to them than others. Furthermore, we need more insights on how older speakers may influence adolescents. Definitely more sociolinguistic and also psycholinguistic research on these questions is required to better understand how language variation and change on the community level interact with an individual's language behaviour.

Acknowledgements: The research for the present article was conducted within the framework of the project "Variation and change of dialect varieties in Austria (in real and apparent time)" by the Austrian Science Foundation (FWF), grant no. F 06002, as part of the Special Research Program "German in Austria” (SFB F 60). We would like to thank Hannes Scheutz and Dominik Wallner for providing the data.

\section{References}

Bailey, Guy, Tom Wikle, Jan Tillery \& Lori Sand. 1991. The apparent time construct. Language Variation and Change 3. 241-264. Buchstaller, Isabelle. 2016. Investigating the effect of socio-cognitive salience and speaker-based factors in morpho-syntactic lifespan change. Journal of English Linguistics 44(3). 199-229.

Buchstaller, Isabelle \& Suzanne Evans Wagner. 2018. Introduction: Using panel data in the sociolinguistic study of variation and change. In Isabelle Buchstaller \& Suzanne E. Wagner (eds.), Panel studies of variation and change, 1-18. London: Routledge.

Bülow, Lars, Hannes Scheutz \& Dominik Wallner. 2019. Variation and change of plural verbs in Salzburg's base dialects. In Antje Dammel \& Oliver Schallert (eds.), Morphological variation: Theoretical and empirical perspectives, 95-134. Amsterdam: Benjamins.

De Decker, Paul. 2006. A real-time investigation of social and phonetic changes in post-adolescence. In Michael L. Friesner \& Maya Ravindranath (eds.), Selected papers from NWAV 34, 65-76. Philadelphia: Penn Working Papers in Linguistics.

Eckert, Penelope. 2000. Linguistic variation as social practice. The linguistic construction of identity in Belten High. Malden, MA: Blackwell Publishers.

Fagot, Delphine, Nathalie Mella, Erika Borella, Paolo Ghisletta, Thierry Lecerf, \& Anik de Ribaupierre. 2018. Intra-individual variability from a lifespan perspective: A comparison of latency and accuracy measures. Journal of Intelligence 6(1). 16. 1-18.

Fisher, Aaron J., John D. Medagliab \& Bertus F. Jeronimus. 2018. Lack of group-to-individual generalizability is a threat to human subjects research. Proceedings of the National Academy of Sciences of the United States of America 115(27). 1-10.

Gregersen, Frans. 2009. The data and design of the LANCHART study. Acta Linguistica Hafniensia 41. 3-29.

Harrington, Jonathan, Sallyanne Palethorpe \& Catherine I. Watson. 2000. Does the queen speak the queen's English? Elizabeth II's traditional pronunciation has been influenced by modern trends. Nature 408(6851). 927-928.

Kranzmayer, Eberhard. 1956. Historische Lautgeographie des gesamtbairischen Dialektraumes. Graz \& Wien: Böhlau.

Labov, William. 1966. The social stratification of English in New York City. Washington, D.C.: Center for Applied Linguistics.

Labov, William. 1975. On the use of the present to explain the past. In Luigi Heilmann (ed.), Proceeding of the $11^{\text {th }}$ International Congress of Linguistics, 825-851. Bologna: II Mulino.

Labov, William. 1994. Principles of linguistic change. Volume I: Internal factors. Oxford: Blackwell.

Larsen-Freeman, Diane \& Lynne Cameron. 2008. Complex systems and applied linguistics. Oxford: Oxford University Press. 
Lowie, Wander. 2017. Lost in state space? Methodological considerations in complex dynamic theory approaches to second language development research. In Lourdes Ortega \& ZhaoHong Han (eds.), Complexity theory and language development: In celebration of Diane Larsen-Freeman, 123-141. Amsterdam \& Philadelphia: Benjamins.

Lowie, Wander \& Marjolijn Verspoor. 2019. Individual differences and the ergodicity problem. Language Learning 69(1). $184-206$.

Molenaar, Peter C. M. \& Cynthia G. Campbell. 2009. The new person-specific paradigm in psychology. Current Trends in Psychology 18. 112-117.

Rickford, John \& Mackenzie Price. 2013. Girlz II women: Age-grading, language change, and stylistic variation. Journal of SocioLinguistics 17(2). 143-179.

Sankoff, Gillian. 2005. Cross-sectional and longitudinal studies in sociolinguistics. In Peter Trudgill (ed.), Sociolinguistics: An international handbook of the science of language and society, 1003-1013. Berlin: Mouton de Gruyter.

Sankoff, Gillian. 2013. Longitudinal studies. In Robert Bayley, Richard Cameron \& Ceil Lucas (eds.), The Oxford handbook of sociolinguistics, 261-279. Oxford: OUP.

Sankoff, Gillian. 2019. Language change across the lifespan: Three trajectory types. Language 95(2). 197-229.

Sankoff, Gillian \& Hélène Blondeau. 2007. Language change across the lifespan: /r/ in montreal French. Language 83. 560-588.

Scheuringer, Hermann. 1990. Sprachentwicklung in Bayern und Österreich. Eine Analyse des Substandardverhaltens der Städte Braunau am Inn (Österreich) und Simbach am Inn (Bayern) und ihres Umlandes. Hamburg: Buske.

Scheutz, Hannes. 1985. Strukturen der Lautveränderung. Variationslinguistische Studien zur Theorie und Empirie sprachlicher Wandlungsprozesse am Beispiel des Mittelbairischen von Ulrichsberg/Oberösterreich. Wien: Braumüller.

Van Geert, Paul. 2011. The contribution of complex dynamic systems to development. Child Development Perspectives 5(4). 273-278.

Van Hofwegen, Janneke \& Walt Wolfram. 2010. Coming of age in African American English: A longitudinal study. Journal of SocioLinguistics 14. 427-455.

Vergeiner, Philip C., Dominik Wallner, Lars Bülow \& Hannes Scheutz. accepted. Redialektalisierung und Alter. Ergebnisse einer real-time-Studie zum Age-grading in Ulrichsberg. In Helen Christen, Brigitte Ganswindt, Joachim Herrgen \& Jürgen Erich Schmidt (eds.), Regiolekt - Der neue Dialekt? Conference volume of 6. Kongress der Internationalen Gesellschaft für Dialektologie des Deutschen (IGDD), 3-15 September 2018. Stuttgart: Steiner.

Wagner, Suzanne Evans. 2012. Age grading in sociolinguistic theory. Language and Linguistics Compass 6(6). 371-382.

Wagner, Suzanne Evans \& Gillian Sankoff. 2011. Age grading in the Montréal French inflected future. Language Variation and Change 23. 275-313.

Wallner, Dominik. in preperation. Sprachwandel in Realtime am Beispiel von Ulrichsberg/Oberösterreich. Salzburg: University of Salzburg dissertation. 